\title{
1H-13C NMR-based profiling of biotechnological starch utilization
}

\author{
Sundekilde, Ulrik K.; Meier, Sebastian
}

Published in:

Analytical Chemistry

Link to article, DOI:

10.1021/acs.analchem.6b02555

Publication date:

2016

Document Version

Peer reviewed version

Link back to DTU Orbit

Citation (APA):
Sundekilde, U. K., \& Meier, S. (2016). ${ }^{1} \mathrm{H}-{ }^{13} \mathrm{C}$ NMR-based profiling of biotechnological starch utilization. Analytical Chemistry, 88(19), 9685-9690. https://doi.org/10.1021/acs.analchem.6b02555

\section{General rights}

Copyright and moral rights for the publications made accessible in the public portal are retained by the authors and/or other copyright owners and it is a condition of accessing publications that users recognise and abide by the legal requirements associated with these rights.

- Users may download and print one copy of any publication from the public portal for the purpose of private study or research.

- You may not further distribute the material or use it for any profit-making activity or commercial gain

- You may freely distribute the URL identifying the publication in the public portal

If you believe that this document breaches copyright please contact us providing details, and we will remove access to the work immediately and investigate your claim. 
Starch from cereals represents the major source of energy in the human diet and has gained additional attention as a source for renewable energy and materials. ${ }^{1-6}$ For its use in biocatalytic and chemocataytic processes, starch often needs to be degraded. In the degradation process of starch and other polysaccharides, chemical detail on degradation reactions is often hard to obtain especially for homopolymers. Hence, analytical challenges remain in characterizing (and optimizing) polysaccharide degradation processes and in the identification of limiting degradation steps.

NMR-based multicomponent analysis of systems with poor chemical shift resolution has been greatly alleviated by technological improvements ${ }^{7,8}$ that bring ${ }^{13} \mathrm{C}$ NMR spectroscopy of complex mixtures at natural ${ }^{13} \mathrm{C}$ abundance into the realms of possibility. ${ }^{9}$ Due to sensitivity (relative to ${ }^{13} \mathrm{C}$ NMR) and resolution gains (relative to ${ }^{1} \mathrm{H}$ and ${ }^{13} \mathrm{C}$ NMR), two-dimensional ${ }^{1} \mathrm{H}^{-13} \mathrm{C}$ NMR is particularly well suited for complex analyses. High-field ${ }^{1} \mathrm{H}^{13} \mathrm{C}$ HSQC NMR spectroscopy provides particular analytical benefits in the discrimination of carbohydrates. ${ }^{10-13}{ }^{1} \mathrm{H}-{ }^{13} \mathrm{C}$ NMR assays may encompass targeted quantitation of smaller mixture components ${ }^{14,15}$ or identify structural motifs in unpurified and underivatized biomass substrates, particularly in lignin and in carbohydrates. ${ }^{16}$

In the study of homopolymer cleavage, the targeted quantitation of intermediate oligomers is less realistic than the analysis of spectral features indicative of different linkages. While optimized ${ }^{1} \mathrm{H}^{-13} \mathrm{C}$ NMR spectroscopy can resolve chemically distinct carbohydrates up to a degree of polymerization of approximately $4-5$, the dependence of the chemical shift on short-range chemical structure impedes the spectral resolution of longer starch fragments and of complex mixtures of starch fragments. In favorable cases, this shortcoming could be addressed through replacing conventional label-free NMR detection by the use of cosolutes. ${ }^{17}$ The rich information content of optimized ${ }^{1} \mathrm{H}_{-}{ }^{13} \mathrm{C}$ NMR spectra is reflected by the detection of hundreds of resolved carbohydrate anomeric signals in plant-derived samples. ${ }^{18}$ Even in the absence of baseline separated signals for targeted quantitative NMR, spectral signatures of starch fragments should be useful to discriminate sample composition and to provide input for the statistical analysis of reaction mixtures.

Here, we use ${ }^{1} \mathrm{H}^{-13} \mathrm{C}$ HSQC spectral features and chemometric analysis for the study of industrial starch- 
degrading processes (Figure 1). Spectral features of the carbohydrate anomeric region in high-resolution ${ }^{1} \mathrm{H}-{ }^{13} \mathrm{C}$ HSQC spectra were expected to contain rich information on process parameters that affect the carbohydrate composition. We thus hypothesized that detailed information on industrial processes using polysaccharide substrates can be obtained using NMR spectra of product samples. Spectral features may classify samples by process conditions, reflect enzyme use in the production process, report on limits of biodegradation or process robustness. ${ }^{19,20}$ In addition, starch degradation might be correlated to quantitative process outcomes such as alcohol formation from starch substrate. In order to assess the use of NMR spectroscopy in the analytical chemistry of starch degrading processes, we thus obtain ${ }^{1} \mathrm{H}^{-13} \mathrm{C}$ HSQC NMR spectra of the anomeric spectral region in 45 commercially produced beer samples and subject them to multivariate analysis.
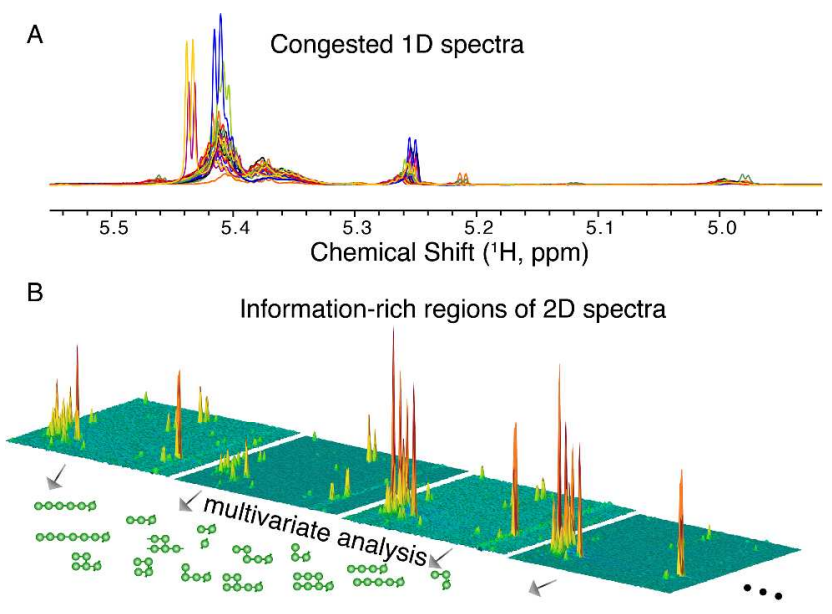

Figure 1. (A) ${ }^{1} \mathrm{H}$ NMR spectral region of the $\alpha$-anomeric carbohydrate signals in commercial beer samples. Except for few outliers, the spectral region is poorly resolved. (B) Multivariate analysis of spectral regions in ${ }^{1} \mathrm{H}^{13} \mathrm{C}$ HSQC informative on starch structure is therefore used herein.

\section{Experimental Section}

\section{Sample preparation}

As representatives of starch-derived biotechnological products, a total of 45 commercially available beers were bought from local super markets. The samples encompassed 3 lambic beers spontaneously fermented by wild yeasts and bacteria as well as 15 ale and 27 lager beers fermented by cultivated yeasts. The alcohol content of the beers ranged from $\mathbf{0 - 1 2} \%$. For one of the samples, replica were purchased with best before dates that were different by at least one month to assess the robustness and reproducibility in production. Samples were prepared by transferring $1 \mathrm{ml}$ of commercial product into an Eppendorf 1.5 $\mathrm{ml}$ safe-lock tube and weighing the transferred sample on a microbalance to obtain accurate volumes of samples. Samples were condensed in a centrifugal evaporator and the non-volatile residue containing all carbohydrates was redissolved in $600 \mu$ of $100 \mathrm{mM}$ phosphate buffer $(\mathrm{pH}$ 7.o) in $\mathrm{D}_{2} \mathrm{O}$ (Cambridge isotopes, Tewksbury, MA, USA). Potassium phosphate buffer in $\mathrm{D}_{2} \mathrm{O}$ was prepared from potassium dihydrogen phosphate (Sigma-Aldrich, Andover, MO, USA) and dipotassium hydrogen phosphate (Sigma-Aldrich) stock solutions of $100 \mathrm{mM}$. Buffer was freeze-dried prior to redissolution in $\mathrm{D}_{2} \mathrm{O}$ to yield $100 \mathrm{mM}$ deuterated buffer. A buffer of $100 \mathrm{mM}$ concentration was chosen as increased salt concentration elicits a sensitivity penalty (lower signal to noise ratio) on NMR systems using cryogenically cooled detection probes.

\section{NMR spectroscopy}

The entire volume of $600 \mu \mathrm{l}$ per sample was transferred to $5 \mathrm{~mm}$ NMR sample tubes. ${ }^{1} \mathrm{H}^{-13} \mathrm{C}$ HSQC spectra of 45 starch-derived samples were acquired at $313 \mathrm{~K}$ on a Bruker (Fällanden) Avance II 8oo spectrometer operating at a ${ }^{13} \mathrm{C}$ frequency of $200.9 \mathrm{MHz}$ and equipped with a 18.7 Tesla magnet (Oxford instruments, Abingdon, UK) and a $5 \mathrm{~mm}$ TCI cryoprobe (Bruker). ${ }^{1} \mathrm{H}-{ }^{13} \mathrm{C}$ HSQC spectra were acquired using a standard Bruker pulse sequence (hsqcetgpsi) with coherence selection by pulsed field gradients and sensitivity enhancement. INEPT transfer times were optimised for ${ }^{1} \mathrm{~J}_{\mathrm{CH}}$ scalar coupling of anomeric ${ }^{1} \mathrm{H}-{ }^{13} \mathrm{C}$ groups with a one-bond coupling on the order of $165 \mathrm{~Hz}$. A data matrix of $512 \times 256$ complex data points was used to sample acquisition times of 160 times and 319 milliseconds in the ${ }^{1} \mathrm{H}$ and ${ }^{13} \mathrm{C}$ dimensions, respectively. Per increment, 4 transients were accumulated with an inter-scan relaxation delay of one second. The spectral width in both dimensions was $4 \mathrm{ppm}$. The resultant total acquisition time per spectra was 46 minutes, comparable to conventional chromatographic runs. Positive projections of $\mathrm{F}_{1}$ were used to generate ${ }^{13} \mathrm{C}$ spectra. Examples of the resultant spectra are shown in Figure $1 \mathrm{~B}$, indicating high signal-to-noise ratio due to the measurements of anomeric signals as sharp lines and due to the use of high-sensitivity NMR equipment. Additional optimization of experimental time or signal-to-noise could include the use of non-uniform sampling schemes or the use of rapid pulsing NMR methods, but was beyond the scope of this study. In addition to ${ }^{1} \mathrm{H}-{ }^{13} \mathrm{C}$ HSQC acquired in this manner, one-dimensional ${ }^{1} \mathrm{H}$ NMR spectra were acquired by sampling 16384 complex data points during an acquisition time of 1.28 seconds with water suppression by presaturation and composite pulse. ${ }^{21}$

\section{Data analysis}

All NMR spectra were acquired and processed in Bruker Topspin 2.1. Processing was performed with extensive zero filling (to 4096 and 1024 points in the ${ }^{1} \mathrm{H}$ and ${ }^{13} \mathrm{C}$ dimensions, respectively) in both dimensions using a shifted squared sine-bell apodization function. Projections of selected spectral regions in the HSQC were produced by producing projections in the ${ }^{1} \mathrm{H}$ chemical shift range of 5.50 to $5.30 \mathrm{ppm}$ containing $\alpha-1,4$ glucopyranosyl linkages, projections in the ${ }^{1} \mathrm{H}$ chemical shift range of 5.04 
to 4.95 ppm containing $\alpha-1,6$ glucopyranosyl linkages, and projections across the entire anomeric spectral region (5.50-4.40 ppm).

Multivariate data analysis techniques were used to examine the carbohydrate profile of ale and lager samples in more detail. An orthogonal partial least squares discriminant analysis ${ }^{22}$ (OPLS-DA) model was developed on the HSQC-derived projections in SIMCA ${ }^{23} 14$ (MKS-Umetrics, Umeå, Sweden). In addition, partial least squares regression (PLSR) was performed on the percentage ethanol by volume also in SIMCA 14 (MKS-Umetrics). The spectral data were normalized to total spectral intensity to account for differences in sample concentration and interspectral variability. Prior to multivariate modeling, the spectra were autoscaled and cross-validated using segmented cross-validation using 4 splits. Models were furthermore tested for validity by 100 -fold permutation tests, in which the response variables (sample class or percentage ethanol by volume) were randomly assigned. Notably, the multivariate approach does not require spectral signals to be quantitative on an absolute scale, which is beneficial as congested HSQC spectra are not easily made absolutely quantitative.

\section{Results \& discussion}

Deciphering the chemical detail of starch fragment composition remains a challenge in the analytical chemistry of foods and of other processes using starch as the substrate. The analytical challenge in analyzing heterogeneous mixtures of maltooligosaccharides and branched oligosaccharides ( $\alpha$-limit dextrins) by conventional ${ }^{1} \mathrm{H}$ NMR is signified by the spectra displayed in Figure $1 \mathrm{~A}$ of the sample set studied herein. The starch fragments appear as broad and congested signals even in high-field (8oo $\mathrm{MHz}$ ) cryo-probe NMR. Glycosidic bond signals of $\alpha$-(1-6)-glucopyranosyl units, for instance, fall within a ${ }^{1} \mathrm{H}$ chemical shift range little larger than o.o1 ppm. The main component of starch is the $\alpha-(1-6)$-branched glucan amylopectin. The limited accessibility of degrading enzymes to $\alpha-(1-4)$ glycosidic bonds in the vicinity of $\alpha-(1-6)$ branch points leaves heterogeneous mixtures of short maltooligosaccharides and branched oligosaccharides $(\alpha-$ limit dextrins) as the primary unused remnants upon biocatalytic starch hydrolysis. ${ }^{24,25}$

Shortcomings in the analysis of carbohydrates by ${ }^{1} \mathrm{H}$ NMR such as the minute chemical shift dispersion and the overlap of the anomeric spectral region with residual water solvent signal were addressed by resorting to ${ }^{1} \mathrm{H}^{13} \mathrm{C}$ NMR spectroscopy (Figure $1 \mathrm{~B}$ ). ${ }^{13} \mathrm{C}$ provides a chemical shift dispersion that is approximately 20 times larger than for ${ }^{1} \mathrm{H}$. Accordingly, several spectral features get resolved in ${ }^{1} \mathrm{H}^{-13} \mathrm{C}$ NMR as compared to ${ }^{1} \mathrm{H}$ NMR. Optimized (nar- row sweep-width) ${ }^{1} \mathrm{H}-{ }^{13} \mathrm{C}$ NMR spectra for two representative samples are shown in Figure 2, yielding a significant number of signals from anomeric $\mathrm{CH}$ groups. Even when using high-resolution twodimensional NMR spectra on a high-field instrument, signals from starch fragments remain overlapped to a certain degree due to the sensitivity of the NMR chemical shift on local structures. Hence, multivariate, non-targeted approaches that do not require absolutely quantitative NMR data were pursued in the statistical analysis of the starch fragment composition as described below. Assignments of structural motives of starch fragments to the overlapped signals were previously established with in situ NMR assignments and through the use of chemically synthesized pure reference standards. ${ }^{26-28}$

Due to the minimal resolution of signals along the ${ }^{1} \mathrm{H}$ NMR dimension, spectral projections of select regions of the ${ }^{1} \mathrm{H}^{13} \mathrm{C}$ NMR spectra onto the ${ }^{13} \mathrm{C}$ dimension were used rather than two-dimensional signals. ${ }^{1} \mathrm{H}^{13} \mathrm{C}$ NMR was thus principally used to gain approximately 30 -fold sensitivity relative to one-dimensional ${ }^{13} \mathrm{C}$ NMR while high resolution in the ${ }^{13} \mathrm{C}$ dimension was achieved by extensive spectral aliasing, employing a spectral width of $4 \mathrm{ppm}$ around the most informative spectral region, the anomeric region containing $\alpha$-glucosidic bonds (97.7-101.7 ppm). In this manner, ${ }^{1} \mathrm{H}-{ }^{13} \mathrm{C}$ NMR yields signals of the anomeric $\mathrm{CH}$ groups with high resolution in the ${ }^{13} \mathrm{C}$ spectral dimension and with significantly improved peak signal to noise ratio relative to one-dimensional ${ }^{13} \mathrm{C}$ NMR spectra and relative to ${ }^{1} \mathrm{H}^{13} \mathrm{C}$ NMR spectra sampling larger sweep widths during the same experiment time.

Projections of the $\alpha-(1-6)$ branch point region for the set of 45 samples as displayed in Figure 3 show that significant variation in the composition and structural motifs present in branched starch fragment mixtures can be detected with ${ }^{13} \mathrm{C}$ NMR spectra information at sufficient signal-to-noise ratios.

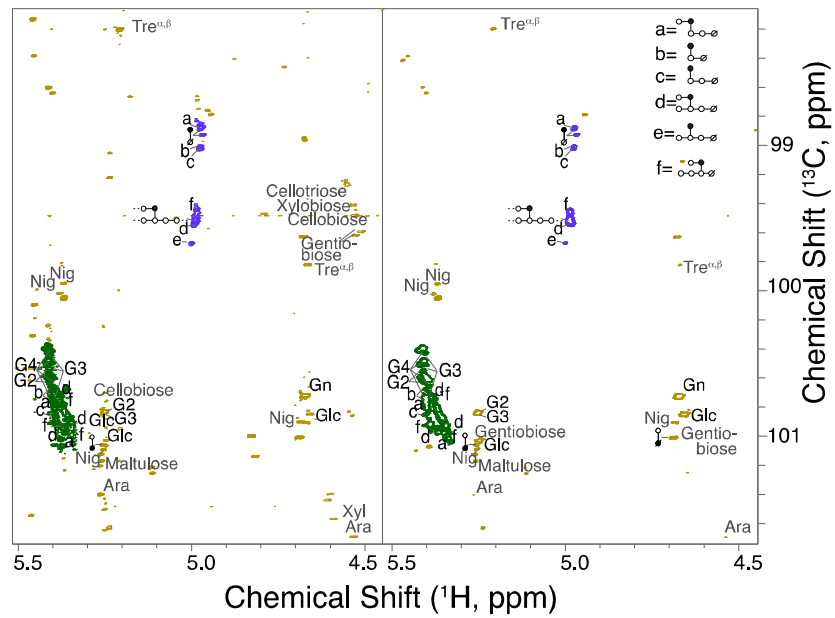

Figure 2. Representative ${ }^{1} \mathrm{H}_{-}{ }^{13} \mathrm{C}$ NMR spectra of lager (left) and ale (right) beer samples recorded with a $4 \mathrm{ppm}$ spectral width in 46 minutes, on a timescale that is comparable to typical chromatographic runs. Some of the major identified signals of starch fragments are labelled. The $\alpha-(1-$ 
6)glucopyraosyl signals are highlighted in blue, while $\alpha$-(14)glucopyraosyl signals are shown in dark green. In the schematic pictograms of limit dextrins, horizontal lines indicate $\alpha-(1-4)$ linkages, vertical lines indicate $\alpha-(1-6)$ linkages, circles indicate glucopyranosyl units and filled circles indicate the structural motif yielding the ${ }^{1} \mathrm{H}-{ }^{13} \mathrm{C}$ signal. $\mathrm{Gn}=$ maltooligosaccharides of length $\mathrm{n}, \mathrm{Ara}=$ arabinose, Glc=glucose, Nig=nigerose, Tre=trehalose.

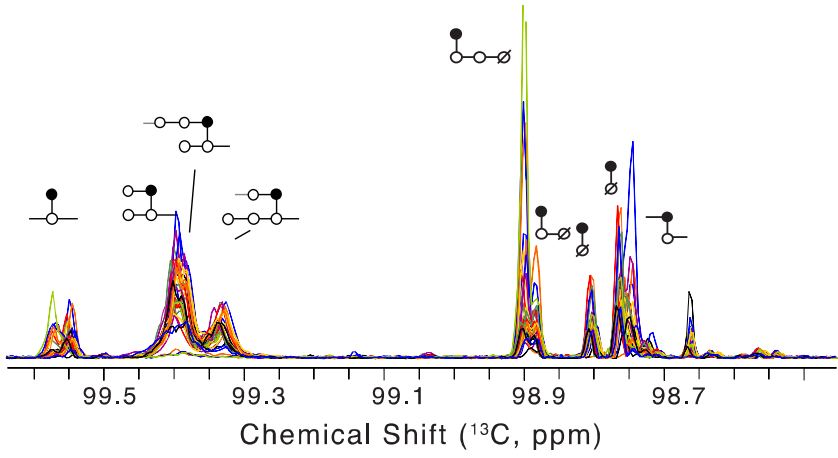

Figure $3 \cdot{ }^{13} \mathrm{C}$ spectral region of $\alpha(1-6)$ glucopyraosyl region as a projection from high-resolution ${ }^{1} \mathrm{H}^{13} \mathrm{C}$ HSQC spectra between $5.04 \mathrm{ppm}$ and $4.95 \mathrm{ppm}$. Corresponding structural motifs in branched starch fragments are displayed with $\alpha(1-$ 6) glycosidic linkages as vertical lines and $\alpha(1-4)$ glycosidic linkages as horizontal lines. Spectral projections reveal a range of differences in limit dextrin composition between the samples.

In order to show that spectral features reflect different production sites (and hence different enzyme and raw material usage) and the use of different production protocols, spectra from different producers and spectra using different production strains (in this instance spontaneously fermented Lambic beers using wild yeasts, topfermented ale beers using Saccharomyces cerevisiae and bottom-fermented lager beers using Saccharomyces pastorianus at low temperatures) were grouped in Figure 4. This grouping indicates that different sample classes may be identifiable from ${ }^{13} \mathrm{C}$ NMR spectral information even by simple inspection. The differences in

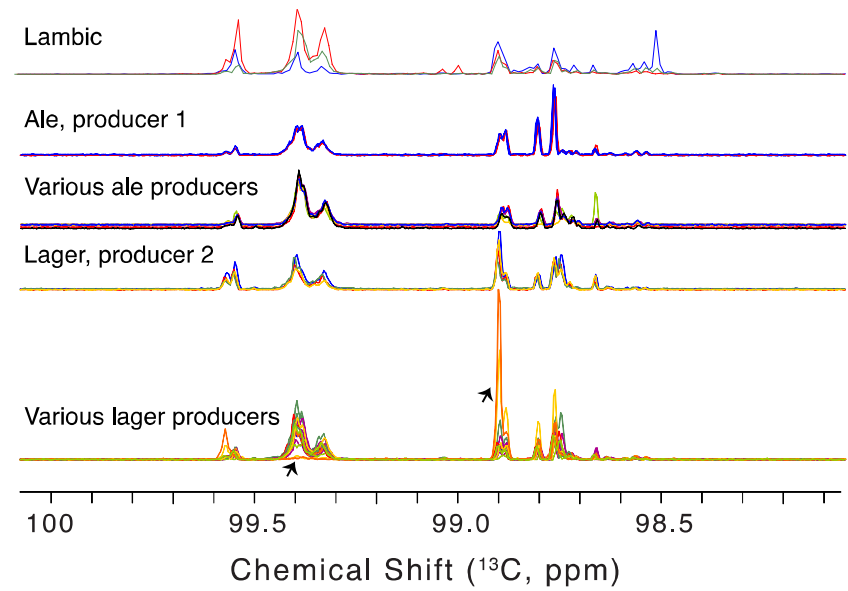

Figure 4. Raw classification of ${ }^{1} \mathrm{H}^{-13} \mathrm{C}$ NMR projections in the $\alpha(1-6)$ glucopyraosyl spectral region of branched (limit dextrin) starch fragments as shown in Figure 2. Spectra of 3 lambic beers, 6 diverse ale beers and samples from two spe- cific beer producers ( 3 ale samples for producer 1 and 4 lager samples of producer 2 ) are extracted from the bulk of samples, indicating that sufficiently highly resolved ${ }^{1} \mathrm{H}^{13} \mathrm{C}$ NMR spectral features of starch degradation products may be useful to spot different producers and different production conditions even without in-depth chemometric analysis.

composition and the varying structural motifs present after biocatalytic treatment are for instance evident by the conversion of complex limit dextrin structures to pruned branch points in some samples (indicated by arrow sin Figure 4).

Such degradation of complex limit dextrin structures results from the exhaustive cleavage of $\alpha-(1-4)$ glycosidic bonds in the vicinity of $\alpha-(1-6)$ branch points, presumably due to extensive use of enzymes in order to increase the degree of fermentation. The purpose of such enzymatic cleavage is the production of fermentable carbohydrates. The optimized, reproducible conversion of starch to fermentable substrates and their actual conversion by fermentation were assessed by comparing products from one selected producer but from different brews (different best before dates). Resultant profiles of starch fragments are displayed in Figure 5. The comparison of different end product batches indicates that starch cleavage to limit dextrins is a process that is well controllable during biotechnological production, yielding only minor inter-batch variation of $\alpha-(1-6)$-branch point signals. In contrast, the production and fermentative usage of small linear oligosaccharides appears to be less consistent in the example of Figure 5, possibly due to poorer control, longer time frame and use of living organisms in the fermentation compared to the mashing process. To further study the effect of different production protocols, spectral projections of the ${ }^{1} \mathrm{H}^{13} \mathrm{C}$ NMR spectra onto the ${ }^{13} \mathrm{C}$ dimension were analyzed by multivariate analysis. The richness of spectral information in the complex carbohydrate spectral regions calls for multivariate approaches to simplify the analysis of larger sample sets and to identify nonobvious distinctive features in the samples. ${ }^{19,20}$ Therefore, chemometric approaches were pursued to extract information from the overlapped spectral features of starch fragments. A similar approach was previously taken in the analysis of cell walls from different ${ }^{1} \mathrm{H}-{ }^{13} \mathrm{C}$ NMR spectral features of lignin compounds. ${ }^{29}$ Opposite to lignin, which is a heteropolymer containing various crosslinks between different phenolic monomers, the chemical shift dispersion in the $\alpha$-glucopyranosyl containing

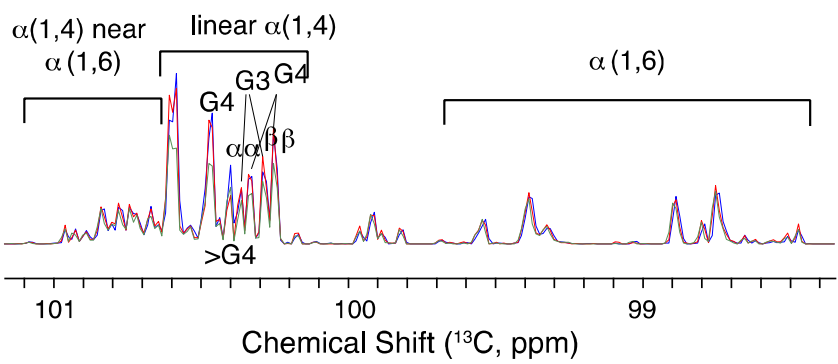


Figure 5. Comparison of identical products from the same producer, but from different batches (different best before dates), indicating that the variance in short maltooligosaccharide structures is larger than the variance in limit dextrin composition.

fragments of homopolymeric amylose and amylopectin is substantially smaller, thus posing distinctive challenges to methodology used for the analysis of polysaccharide linkages as compared to analysis of lignin linkages.

In the present study, spectral projections in the ${ }^{13} \mathrm{C} \mathrm{di}-$ mension were used rather than two-dimensional signals to study the difference in starch fragments between samples using different types of yeasts in production. The use of projections from informative spectral regions of the $2 \mathrm{D}$ spectrum permits the use of well-established multivariate analysis methods for one-dimensional spectral data. The projections were used for generating an OPLS-DA model capable of classification of samples into lager and ale beer types (Figure 6, Supporting Figure S2). For interpretation, the OPLS-DA loadings were back-scaled and each variable was plotted with a color corresponding to its weight (Figure 6B). ${ }^{30}$ Ale samples were found to have increased levels of the unfermentable disaccharide nigerose $(3-O-\alpha-$ D-glucopyranosyl-D-glucose; Figure 6B). Differences between sample types as identified by OPLS-DA were mostly related to $\alpha-(1-6)$ glycosidic linkages in starch fragments (Figure 6B). Ale samples had increased levels of complex limit dextrins, whereas lager samples had increased levels of shorter limit dextrins. The OPLS-DA model improves slightly by using spectral features over the entire anomeric carbohydrate region rather than just those of starch fragments, thus underlining some contribution of signals from smaller sugars in the distinction of different production conditions.

As spectral signatures of carbohydrates can be used to accurately classify production conditions (Figure 6A), we assessed the predictive value of carbohydrate profiles for percentage ethanol by volume in the samples. Ethanol content is used as a reliably quantifiable parameter to showcase the prediction of chemical production from feedstock structure with high-resolution NMR data. Samples with low or high ethanol concentration were excluded from the sample set prior to modeling, as additional processing may be taken to reach these levels of alcohol (see supplemental figure $S_{1}$ for the full data set). Partial least squares regression (PLSR) was thus performed on 27 samples, without the extreme values of percentage ethanol by volume, using percentage ethanol by volume as indicated on the product label and spectral projections of the full anomeric region of starch fragments (range 10198.3 ppm) in the ${ }^{13} \mathrm{C}$ dimension (Figure 7). Three PLS components were used and the model were validated using segmented cross-validation using 4 splits. Also the PLSR model was tested for validity using 100-fold permutation tests (Supporting Figure $\mathrm{S}_{3}$ ).
A

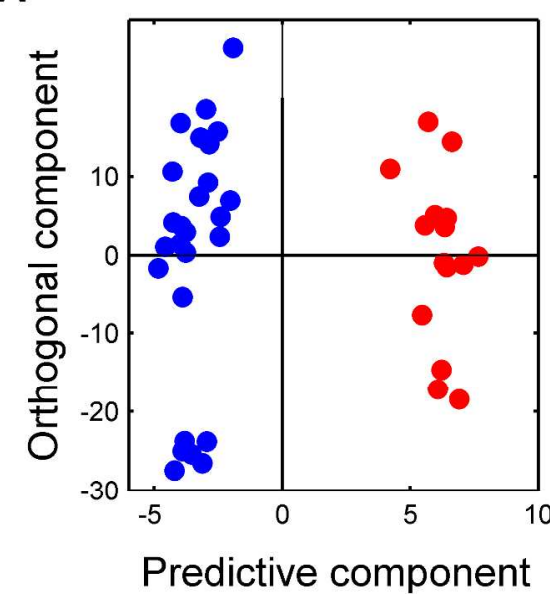

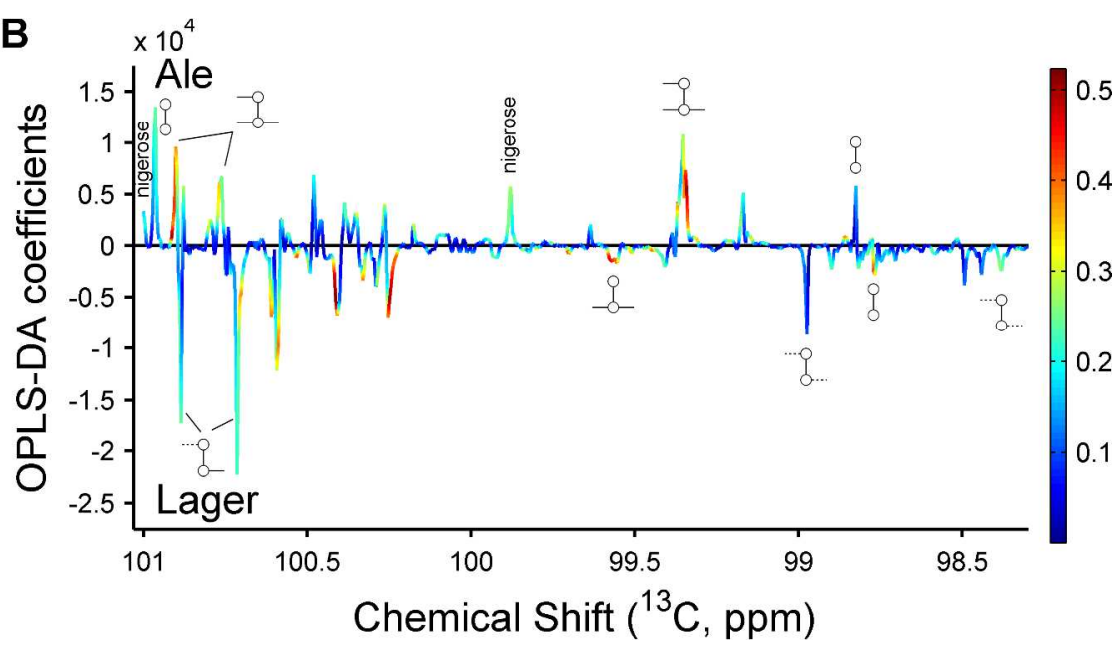

Figure 6. OPLS-DA model on spectral features of starch fragments $\left({ }^{13} \mathrm{C}\right.$ projections in the range $98.3-101.0$ ppm of ${ }^{1} \mathrm{H}-{ }^{13} \mathrm{C}$ spectra of ale and lager). Coefficient of determination $\left(\mathrm{R}^{2}\right)=0.67 \mathrm{Q}^{2}=0.60$. A) OPLS-DA scores plot of lager (red) and ale (blue) samples. B) S-line plot.

Table 1: The important spectral features by Variable Importance in Projection (VIP) and their regression coefficients of the PLS regression model shown in Figure 7 . Number of PLS components: 3. Coefficient of determination $\left(R^{2}\right)=0.67$, $\mathrm{Q}^{2}=0.62$. RMSECV: 0.53

\begin{tabular}{cccl}
${ }^{13} \mathrm{C} \delta, \mathrm{ppm}$ & Assignment & $\mathrm{VIP}^{1}$ & reg coef \\
\hline $\mathbf{1 0 0 . 5 2}$ & -0 & 1.88 & -0.01
\end{tabular}

100.36

99.54

99.51

99.45

99.40

99.37

$99 \cdot 31$ maltooligosaccha-

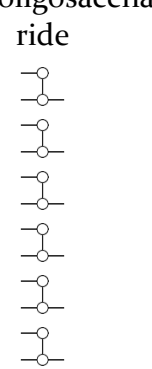

1.98

1.90

1.98

1.85

1.72

1.70

1.86
0.02

0.02

$-0.02$

$-0.02$

$-0.02$

0.02

0.02 
$-0.01$

${ }^{1}$ variable importance in projection

${ }^{2}$ regression coefficient of variable

The regression coefficients shown in Table 1 indicated some spectral features important in the prediction of percentage ethanol by volume, mostly $\alpha-(1-6)$ glycosidic linkages in starch fragments. Correlation coefficients showed that various carbohydrates contribute to the prediction of percentage ethanol by volume. The consistent correlation of percentage ethanol by volume with starch fragment profiles thus may reflect the use of comparable methods for controlling percentage ethanol by volume by different producers. Including high- and low-alcohol samples in the model reduces the multiple correlation coefficient $\mathrm{R}^{2}$ from 0.67 to 0.45 and the criterion for predictive relevance $\left(Q^{2}\right)$ from 0.62 to 0.15 . This decrease in the predictive power of the model is consistent with the use of additional means beyond starch usage for controlling extreme values of percentage ethanol by volume, such as high-gravity fermentation and the removal or addition of alcohol by various means. More generally, correlation of ${ }^{1} \mathrm{H}-{ }^{13} \mathrm{C}$ NMR data of starch fragments to other chemical composition may thus facilitate the identification of post-process sample modification or the use of suboptimal production conditions in various chemocatalytic and biotechnological processes.

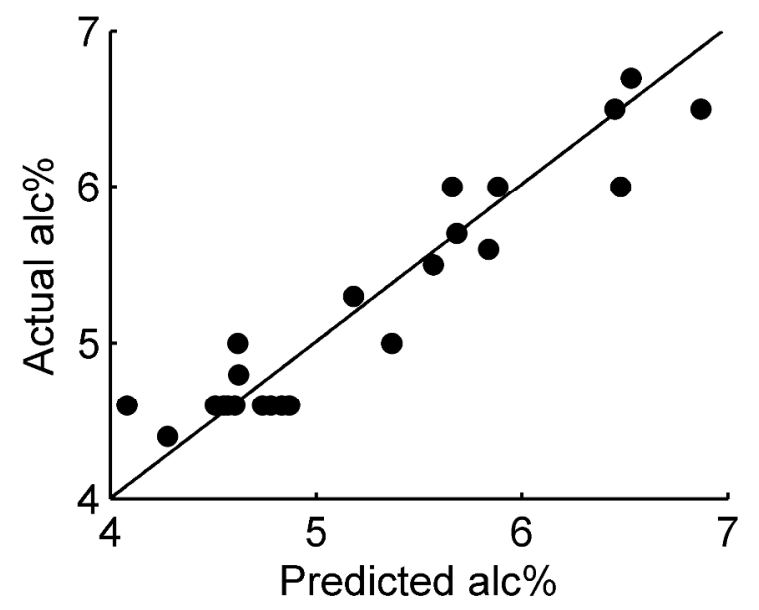

Figure 7. PLS regression on beer samples with percentage ethanol by volume in the range $4 \cdot 4-7 \cdot 5 \%(\mathrm{n}=27)$. Actual versus predicted alcohol percentages are plotted using remaining starch fragments as the predictive spectral features $\left({ }^{13} \mathrm{C}\right.$ projections in the spectra region from 98.3-101.0 ppm). Number of PLS components: 3. Coefficient of determination $\left(\mathrm{R}^{2}\right)=0.67, \mathrm{Q}^{2}=0.62$. RMSECV: 0.53 .

\section{Conclusion}

${ }^{1} \mathrm{H}^{-{ }^{13} \mathrm{C}}$ NMR spectroscopy has gained popularity in the analysis of complex mixtures due to high signal separation, potentially resolving $>10^{5}$ individual signals for small analytes with narrow line widths relative to the chemical shift range. Due to this analytical prowess, ${ }^{1} \mathrm{H}^{13} \mathrm{C}$ NMR spectroscopy emerges as a method for the non-targeted characterization of complex mixtures of renewable biomass, including lignin and polysaccharide fragments. We show that simple inspection and chemometric approaches applied to ${ }^{1} \mathrm{H}^{13} \mathrm{C}$ spectral data reveal detailed, nonobvious information from the homooligomeric starch fragments produced in industrial workstreams. Starch fragments can be consistently correlated with known sample properties, specifically with production conditions (different temperature and microbial strains for ale and lager sample types, respectively) and with percentage ethanol by volume. While ${ }^{1} \mathrm{H}$ NMR had proven useful to achieve some spectral distinction of ale and lager samples, no full separation of the groups had been achieved from their carbohydrate signals. In contrast, the additional information provided by ${ }^{1} \mathrm{H}^{-13} \mathrm{C}$ NMR spectra permits a separation of both sample groups by the starch fragment profiles only, consistent with the much larger signal dispersion in the ${ }^{13} \mathrm{C}$ spectral dimension. Starch utilization is a common aspect in the production of the samples utilized herein. The distinction of starch-utilizing workstreams by ${ }^{1} \mathrm{H}^{13} \mathrm{C}$ NMR spectral signatures of homooligomeric substrate fragments is encouraging for the use of ${ }^{1} \mathrm{H}-{ }^{13} \mathrm{C}$ NMR spectroscopy in processes involving the formation or degradation of polysaccharides.

\section{ASSOCIATED CONTENT}

Supporting Information

Supporting Information Available: Supplemental figures S1-S4. This material is available free of charge via the Internet at http://pubs.acs.org.

\section{AUTHOR INFORMATION}

Corresponding Authors

*Email uksundekilde@food.au.dk or semei@kemi.dtu.dk.

Notes

The authors declare no competing financial interest.

\section{ACKNOWLEDGMENT}

UKS gratefully acknowledge funding by Arla Foods amba. SM gratefully acknowledges funding by Grant 2013_01_0709 of the Carlsberg Foundation. 8oo MHz NMR spectra were recorded on the spectrometer of the National Instrument Center for NMR Spectroscopy of Biological Macromolecules at the Technical University of Denmark.

\section{REFERENCES}


(1) Zhang, Y. H.; Evans, B. R.; Mielenz, J. R.; Hopkins, R. C.; Adams, M. W. PloS one $\mathbf{2 0 0 7}, 2$, e456.

(2) Niessen, J.; Schröder, U.; Scholz, F. Electrochem. Comm. 2004, 6, 955-958.

(3) Krishnan, M. S.; Taylor, F.; Davison, B. H.; Nghiem, N. P. Biores. Tech. 2000, 75, 99-105.

(4) Gandini, A. Green Chem. 2011, 13, 1061-1083.

(5) van Putten, R.-J.; van der Waal, J. C.; de Jong, E.; Rasrendra, C. B.; Heeres, H. J.; de Vries, J. G. Chem. Rev. 2013, 113, 14991597.

(6) Gandini, A.; Lacerda, T. M.; Carvalho, A. J. F.; Trovatti, E. Chem. Rev. 2016, 116, 1637-1669.

(7) Styles, P.; Soffe, N. F.; Scott, C. A.; Crag, D. A.; Row, F.; White, D. J.; White, P. C. J. J. Mag. Res. 1984, 6o, 397-404.

(8) Kovacs, H.; Moskau, D.; Spraul, M. Prog. Nuc. Mag. Res. Sp. 2005, 46, 131-155.

(9) Keun, H. C.; Beckonert, O.; Griffin, J. L.; Richter, C.; Moskau, D.; Lindon, J. C.; Nicholson, J. K. Anal. Chem. 2002, 74, 4588-4593.

(10) Petersen, B. O.; Olsen, O.; Beeren, S. R.; Hindsgaul, O.; Meier, S. Carbohyd. Res. 2013, 368, 47-51.

(11) Petersen, B. O.; Lok, F.; Meier, S. Carbohyd. Pol. 2014, 112, 587-594.

(12) Zhang, L.; Gellerstedt, G. Mag. Res. Chem. 2007, 45, 37-45.

(13) Xi, Y.; de Ropp, J. S.; Viant, M. R.; Woodruff, D. L.; Yu, P. Anal. Chim. Acta 2008, 614, 127-133.

(14) Lewis, I. A.; Schommer, S. C.; Hodis, B.; Robb, K. A.; Tonelli, M.; Westler, W. M.; Sussman, M. R.; Markley, J. L. Anal. Chem. 2007, 79, 9385-9390.

(15) Gronwald, W.; Klein, M. S.; Kaspar, H.; Fagerer, S. R.; Nürnberger, N.; Dettmer, K.; Bertsch, T.; Oefner, P. J. Anal. Chem. 2008, 8o, 9288-9297.

(16) Wen, J.-L.; Sun, S.-L.; Xue, B.-L.; Sun, R.-C. Materials 2013, 6.
(17) Beeren, S. R.; Meier, S. Chem. Comm. 2015, 51, 3073-3076.

(18) Meier, S. Anal. Bioanal. Chem. 2014, 406, 7763-7772.

(19) Duarte, I.; Barros, A.; Belton, P. S.; Righelato, R.; Spraul, M.; Humpfer, E.; Gil, A. M. J. Agr. Food Chem. 2002, 50, 24752481.

(20) Duarte, I. F.; Godejohann, M.; Braumann, U.; Spraul, M.; Gil, A. M. J. Agr. Food Chem. 2003, 51, 4847-4852.

(21) Bax, A. J. Mag. Res. 1985, 65, 142-145.

(22) Bylesjö, M.; Rantalainen, M.; Cloarec, O.; Nicholson, J. K.; Holmes, E.; Trygg, J. Journal of Chemometrics 2006, 20, 341-351.

(23) Wold, S.; Sjöström, M. In Chemometrics: Theory and Application; 1977, pp 243-282.

(24) Petersen, B. O.; Nilsson, M.; Bojstrup, M.; Hindsgaul, O.; Meier, S. Food Chem. 2014, 150, 65-72.

(25) Møller, M. S.; Windahl, M. S.; Sim, L.; Bøjstrup, M.; Abou Hachem, M.; Hindsgaul, O.; Palcic, M.; Svensson, B.; Henriksen, A. J. Mol. Biol. 2015, 427, 1263-1277.

(26) Jodelet, A.; Rigby, N. M.; Colquhoun, I. J. Carb. Res. 1998, 312, 139-151.

(27) Beeren, S. R.; Petersen, B. O.; Bojstrup, M.; Hindsgaul, O.; Meier, S. ChemBioChem 2013, 14, 2506-2511.

(28) Petersen, B. O.; Motawie, M. S.; Moller, B. L.; Hindsgaul, O.; Meier, S. Carb. Res. 2015, 403, 149-156.

(29) Hedenström, M.; Wiklund-Lindström, S.; Öman, T.; Lu, F.; Gerber, L.; Schatz, P.; Sundberg, B.; Ralph, J. Molecular Plant, 2, 933-942.

(30) Cloarec, O.; Dumas, M. E.; Trygg, J.; Craig, A.; Barton, R. H.; Lindon, J. C.; Nicholson, J. K.; Holmes, E. Anal. Chem. 2005, 77, 517-526. 


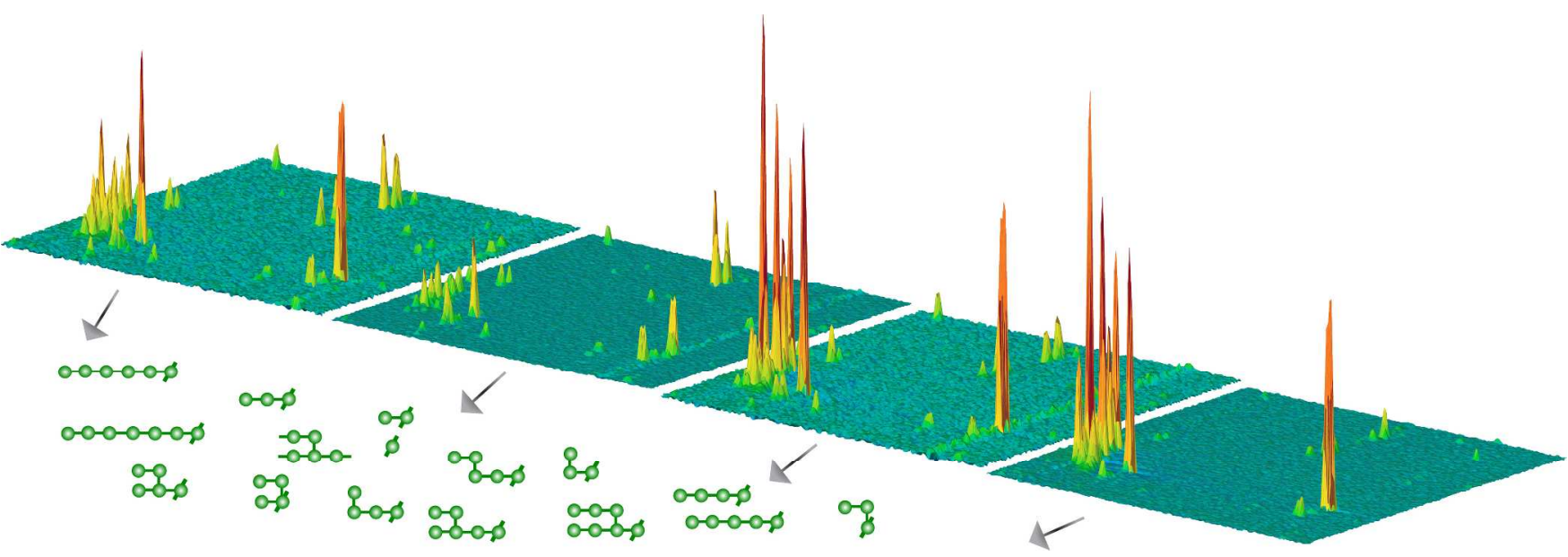

